\title{
Purification Treatment on Polluted River via Combinations of Gravel Contact Oxidation Treatment and Surface Flow Constructed Wetlands-A Case Study in Changhua County, Taiwan
}

\author{
Chen-Chiang Chou 1, Wei-Ting Chen ${ }^{2, *}$, and Yung-Pin Tsai ${ }^{3, *}$ \\ 1 Doctoral Program, Department of Civil Engineering, National Chi Nan University, Nantou 545, Taiwan; \\ ccc6166@yahoo.com.tw \\ 2 Department of Cosmetic Application \& Management, St. Mary's Junior College of Medicine, \\ Nursing and Management, Yilan 266, Taiwan \\ 3 Department of Civil Engineering, National Chi Nan University, Nantou 545, Taiwan \\ * Correspondence: chenwt@smc.edu.tw (W.-T.C.); yptsai@ncnu.edu.tw (Y.-P.T.); \\ Tel.: +886-3-989-7393 (ext. 651) (W.-T.C.); +886-49-291-0960 (ext. 4959) (Y.-P.T.)
}

\begin{abstract}
Polluted rivers are a primary problem in Changhua County, Taiwan, due to rapid and massive developments in agriculture and industry. In this study, samples consisted of water influent from the Yangzi-Cuo River, Ci-Tong Jiao, Changhua County. Ecology technology, a combination of gravel contact oxidation and surface flow constructed wetlands, was employed to enhance the water quality. Ecology technology is a useful and ordinary process that focuses on original treatment of pollution through chemical, physical, and biological procedures based on the mediums of soil, plant, water, and microorganisms from pure environments. Moreover, this study aimed to minimize the river pollution index (RPI) of the Yangzi-Cuo River by using combinations of gravel contact oxidation and surface flow constructed wetlands. The inflow volume of the water samples in situ was found to be 1534-2261 cubic meters per day (CMD). The pollution in the water sample mostly involved suspended solid (SS), ammoniacal nitrogen $\left(\mathrm{NH}_{3}-\mathrm{N}\right)$, total phosphorus (TP), total nitrogen (TN), and biochemical oxygen demand (BOD), and the values of the above indexes were found to be $10.0-26.7 \mathrm{mg} / \mathrm{L}, 0.9-14.0 \mathrm{mg} / \mathrm{L}, 1.2-14.1 \mathrm{mg} / \mathrm{L}, 11.1-18.2 \mathrm{mg} / \mathrm{L}$, and 0.5-3.6 mg/L, respectively. Efficiencies of pollution elimination in $\mathrm{SS}, \mathrm{NH}_{3}-\mathrm{N}, \mathrm{TP}, \mathrm{TN}$, and BOD were found to be $24.2-93.1 \%, 58.3-86.2 \%, 5.2-85.0 \%, 59.4-77.2 \%$, and $46.3-76.4 \%$, correspondingly, after purification treatment via ecology technology. Thus, ecology technology is a valid means of purification treatment for polluted rivers.
\end{abstract}

Keywords: ecology technology; gravel contact oxidation; surface flow constructed wetlands; water quality; river pollution index

\section{Introduction}

Household wastewater is a type of pollution generated from human beings' daily activities. Excrement from human beings and domesticated animals has generally been used to culture crops over the past five decades. Household wastewater is discharged into rivers and soil, and their self-purification functions degrade these low-grade toxic and uncomplicated wastes [1-5]. However, population centralization, the enhancement in living quality, the development of technology, and variations in living style have resulted in an increase in discharged wastewater 
with more complicated water content, which such rivers and soil, with their self-purification functions, cannot handle. As a result, river and soil pollution is becoming increasingly serious. Industrial and agricultural activities are central to the economy of Changhua County, and the population of Changhua County has reached 1.3 million, consequently increasing this wastewater. Based on the estimated historical data from the Environment Protection Administration (EPA), river pollution in Taiwan has been due to industrial wastewater in the past five decades, and, after the implementation of environment protection regulations, the problem of industrial wastewater has been resolved.

However, approximately $47 \%$ of wastewater production comes from households, and such household wastewater is now the most serious issue in terms of wastewater production in Taiwan. Moreover, the popularizing rate of public sewage treatment was only $6.3 \%$ at 2008 in Changhua County, and most household wastewater, with the rain, is usually discharged directly into rivers through a drain. As a result, discharged household wastewater dramatically degrades the water quality of river. There are many purification technologies, including membrane filtration, wet pyrolysis, coagulation, and anaerobic digestion [6-9], used in waste and wastewater treatment. In addition, the EPA have started to announce policies and strategies regarding wastewater pollution treatment to the local government since 2002. The announced method included gravel contact oxidation treatment, surface flow constructed wetlands, and an aeration facility for wastewater purification [10-18]. The principle of such wastewater purification is the interaction of wastewater and natural environmental factors, such as oxygen, soil, microorganism, and plants, and the aim is to purify water quality and thus eliminate the pollution of rivers via the decrease of discharged wastewater.

The onsite wastewater treatment system (OWTS) is a novel ecological engineering designed to improve river quality in Taiwan. The efficiency of the OWTS strives for wastewater treatment and water quality purification via natural mechanisms and energy, and the mechanism is described as using fundamentally physical, chemical, and biological methods with consideration of onsite environmental conditions, including pollution category, soil quality, gradient value, flow rate, and gravel type, to achieve maximum efficiency in wastewater treatment. Metcalf and Eddy [19] declared that there were two natural wastewater treatment systems, including a soil/land treatment system and an aquatic-based treatment system, and these two systems consisted of individual methods. The soil/land treatment system contained slow rate, rapid infiltration, and overland flow methods, and the aquatic-based treatment system involved surface flow constructed wetland, natural wetland, and aquatic plant methods. However, gravel contact oxidation treatment is the most common method used in Taiwan, and this method was initially developed by the Japanese government for river quality purification [20].

The EPA collected domestic river quality data in 25 locations by conducting a project with a river quality purification technology design in 2005-2006 and then summarized the results. The variation in biochemical oxygen demand (BOD), ammonia nitrogen $\left(\mathrm{NH}_{3}-\mathrm{N}\right)$, total phosphorus (TP), and suspended solid (SS) presents efficiency in wastewater pollution removal via gravel contact oxidation treatment, and this can be applied as a reference for the operation of river quality natural purification treatment. As a result, this study employed gravel contact oxidation treatment to purify the water quality of the Yangzi-Cuo River in Ci-Tong Jiao, Changhua County.

\section{Experimental and Methodology}

\subsection{Introduction of Gravel Contact Oxidation Treatment}

Gravel contact oxidation treatment is a fast method compared to other natural purification technologies, and its principle is that wastewater, after it has flown rapidly through gravel, can be decomposed by the bio-membranes attached to the gravel [21]. Gravel is the main component used in gravel contact oxidation treatment, but material with a particle diameter of $0.6-1.2 \mathrm{~mm}$, as a subordinate substance, can also be used. For instance, coal cinder and coke are also suitable for application in this treatment. There is usually a two-layer arrangement of gravel to enhance the 
efficiency of wastewater decomposition, and the intervals of the upper and lower gravel layers are loose and tight, respectively. Furthermore, the flow rate is high to maintain an aerobic status in the upper layer, and is low to maintain an anaerobic status in the lower layer. The condition of the two gravel layers is defined as a double contact system, and the average hydraulic loading rate (HLR) is approximately $0.47 \mathrm{~m} /$ day. Particle diameter is the priority factor in wastewater pollution treatment, and the flow rate is rather slow if the particle size is too small to result in a high efficiency of wastewater pollution removal. Moreover, Seidel [22] investigated that gravel with a particle size less than $0.06 \mathrm{~m}$ is suitable for aquatic plant growth because such an environment provides a surface area that is high enough for many microorganisms to attach to, and this allows for the growth of the aquatic plant.

Based on Darcy's law [23-27], relationships regarding water flow rate in sand filters were determined through a report on the construction of the Dijon municipal water system in France. The volume flow rate $(q)$ is represented as a gradient of elevation $(z)$ in the horizontal direction of water flow $(x)$. Equation (1) was used to describe the relationship of $Q, z$, and $x$ :

$$
q=-K_{s} \frac{d z}{d x}
$$

where $q$ is the volume flow rate; $K_{s}$ symbolizes the saturated hydraulic conductivity; $z$ represents the gradient of elevation; and $x$ depicts the horizontal direction of water flow. Moreover, Equation (2) discussed the connection of $q$ and the volume flow rate of underwater $(Q)$.

$$
Q=q A
$$

where $Q$ stands for the volume flow rate underwater, and $A$ describes the area of the gravel wetland. In a more detailed way, multiplication of the gradient of elevation and the width of the wetland ( $l$ yields an outcome of $A$, as depicted in Equation (3), where $l$ is the width of the wetland.

$$
A=l z \text {. }
$$

Equation (4) can be obtained after the substitution of Equations (2) and (3) into Equation (1), as shown in the following equation.

$$
Q=-K_{s} l z \frac{d z}{d x}
$$

After integration on both sides of the equal sign, Equation (5) can be acquired, and is illustrated as follows:

$$
Q \int_{0}^{x} d x=-K_{s} l \int_{z 0}^{z} z d z
$$

where $z 0$ represents the initial elevation of inflow, and $z$ stands for the current elevation of inflow at any time. A summary of Equation (5) can present the outcome of Equation (6), shown in the following equation.

$$
\frac{2 Q x}{K_{s} l}=z_{0}^{2}-z^{2} .
$$

Furthermore, Equation (5) can also depict a different functional equation, as shown in Equation (7):

$$
z=\sqrt{z_{0}^{2}-\frac{2 Q}{K_{s} l} x} .
$$

Equation (8) mentions the hydraulic retention time (HRT) of the flow in the wetland and is as follows: 


$$
H R T=\frac{V}{Q}
$$

where HRT represents the hydraulic retention time, and $V$ is the volume of the water inside the wetland. Moreover, $V$ is calculated by the multiplication of porosity $(\varphi)$, the width of the wetland $(l)$, the elevation $(z)$, and the horizontal direction of the water flow $(x)$, as depicted in Equation (9):

$$
V=\phi l z x
$$

where $\varphi$ represents porosity.

Equation (10) can be derived from the calculation of Equation (8) as follows:

$$
d H R T=\frac{d V}{d Q}
$$

After the substitution of Equation (9) to Equation (10), a new combination can be acquired, as illustrated in Equation (11):

$$
d H R T=\frac{\phi l}{Q} z d x
$$

In addition, the substitution of Equation (7) to Equation (11) can derive Equation (12), presented in the following equation.

$$
\int_{0}^{H R T} d H R T=\frac{\phi l}{Q} \int_{0}^{x}\left(z_{0}^{2}-\frac{2 Q}{K_{s} l} x\right)^{1 / 2} d x .
$$

Equation (13) can be obtained by summary of Equation (12) as follows:

$$
H R T=\frac{\phi K_{s} l^{2}}{3 Q^{2}} z_{0}^{3}\left[1-\left(1-\frac{2 Q}{K_{s} l z_{0}^{2}} x\right)^{3 / 2}\right] \text {. }
$$

In the assumption situation, a first-order reaction can match the condition of wastewater purification in the wetland, and the above condition can be described in Equation (14), as depicted in the following equation.

$$
C=C_{0} e^{-k H R T}
$$

where $C_{0}$ represents the concentration of the inflow; $C$ is the concentration of the outflow; $k$ depicts the coefficient of the first-order reaction.

According to the perspective of Equations (13) and (14), a decomposition reaction of wastewater pollution can be presented, and the two factors of $k$ and HRT are very important among those hydraulic parameters. Furthermore, the value of HRT varies according to many factors, such as saturated hydraulic conductivity $\left(K_{s}\right)$, porosity $(\varphi)$, volume of flow, and elevation $(z)$. The factors of hydraulic conductivity $\left(K_{s}\right)$ and porosity $(\varphi)$ are useful for the construction, and the operational situation of the wetland is determined by the volume of flow and elevation $(z)$. Decomposition reaction of pollution is altered by the growth condition of the biomembrane.

\subsection{The Proper Design Processes of a Constructed Wetland}

There are six core processes to design a constructed wetland, and those processes are listed as follows:

(1) estimation of the amount of rainfall via collection of atmospheric data in a specific area;

(2) evaluation of the amount of vaporization by an evaporation pan method and an on-site evaporating test; 
(3) calculation of soil infiltration data;

(4) calculation of HRT, the volume of flow, and the design area of the constructed wetland by applying a first-order model - the $\mathrm{k}-\mathrm{C}^{*}$ model (common used in the surface flow wetland) or the Monod kinetics model (general applied in the subsurface flow wetland) with consideration of environmental temperature and species of pollution [28];

(5) computation of the average volume of flow via hydrographic data for adjusting the volume of flow and the design area;

(6) collection of geographical data of the constructed wetland.

The conditions of wastewater treatments in this study are described in table 1, as shown as follows. The wastewater treatments are dived as two main methods in this study, including gravel contact oxidation and constructed wetland. Total base area and water purification treatment area are designed as 9,000 square meter and 730 square meter, respectively. The inflow source is originally exhausted from household wastewater in ci-tong jiao, Changhua County with its coordinate position of $(23.070949,120.505699)$. Moreover, gravity type and pumping motor diversions were applied as inflow way with the treatment capacity of $2000 \mathrm{CMD}$, and hydraulic retention time (HRT) remained as 2.59 days. The original inflow concentrations of BOD5, $\mathrm{NH}_{3}-\mathrm{N}$, $\mathrm{SS}$, and TP are $50 \mathrm{mg} / \mathrm{L}, 80 \mathrm{mg} / \mathrm{L}, 50 \mathrm{mg} / \mathrm{L}$, and $2.6 \mathrm{mg} / \mathrm{L}$, correspondingly, and the exhausted outflow concentrations of BOD5, $\mathrm{NH}_{3}-\mathrm{N}, \mathrm{SS}$, and $1.0 \mathrm{mg} / \mathrm{L}$ turn to $20 \mathrm{mg} / \mathrm{L}, 48 \mathrm{mg} / \mathrm{L}, 20 \mathrm{mg} / \mathrm{L}$, and $1.0 \mathrm{mg} / \mathrm{L}$, respectively, after wastewater treatments. As the result, the removal efficiency of BOD5, $\mathrm{NH}_{3}-\mathrm{N}$, SS, and TP are $60 \%, 40 \%, 60 \%$, and $60 \%$, respectively, and the removal capacity of BOD5, $\mathrm{NH}_{3}-\mathrm{N}, \mathrm{SS}$, and TP are $20 \mathrm{Kg} / \mathrm{D},<5 \mathrm{Kg} / \mathrm{D},<20 \mathrm{Kg} / \mathrm{D}$, and $<5 \mathrm{Kg} / \mathrm{D}$, correspondingly. Expectation of purified outflow concentration of BOD5, $\mathrm{NH}_{3}-\mathrm{N}$, SS, and TP depict as $20 \mathrm{mg} / \mathrm{L}, 5 \mathrm{mg} / \mathrm{L}, 20 \mathrm{mg} / \mathrm{L}$, and $5 \mathrm{mg} / \mathrm{L}$, respectively.

\section{Results and Discussion}

\subsection{Removal Efficiency of SS}

The initial SS concentration of inflow ranged from 12.0 to $62.0 \mathrm{mg} / \mathrm{L}$, and the removal efficiency of the wastewater via gravel contact oxidation was 3-75\%, as shown in Figure 1a. The removal efficiency of wastewater tends to be high if the inflow concentration is high. As a result, SS can be easily removed by using gravel contact oxidation treatment. Furthermore, removal efficiency changed dramatically when the inflow concentration was lower than $20 \mathrm{mg} / \mathrm{L}$, resulting in an obscured outcome. The SS concentration of outflow was less than $20 \mathrm{mg} / \mathrm{L}$ after gravel contact oxidation treatment. Removal efficiency of the surface flow constructed wetlands also changed dramatically. Figure $1 \mathrm{~b}$ shows that the SS concentration of outflow was $15.2 \mathrm{mg} / \mathrm{L}$ in October. Decomposition of fallen leaves from aquatic plants, deposit releases from the bottom, and biomembranes dropped in the outflow of constructed wetlands, resulting in the background concentration of SS. Moreover, treatment loading increased and SS concentration was enhanced, and the removal efficiency of the combined system ranged from 46 to $96 \%$, as depicted in Figure 1c. Furthermore, a sedimentation basin could be used to collect sands with a particle diameter above 2 $\mathrm{mm}$ to prevent them from flowing to the gravel contact oxidation tank without a primary sand filter, resulting in, due to the sand accumulation, a reduction in the use capacity of the gravel contact oxidation tank. 


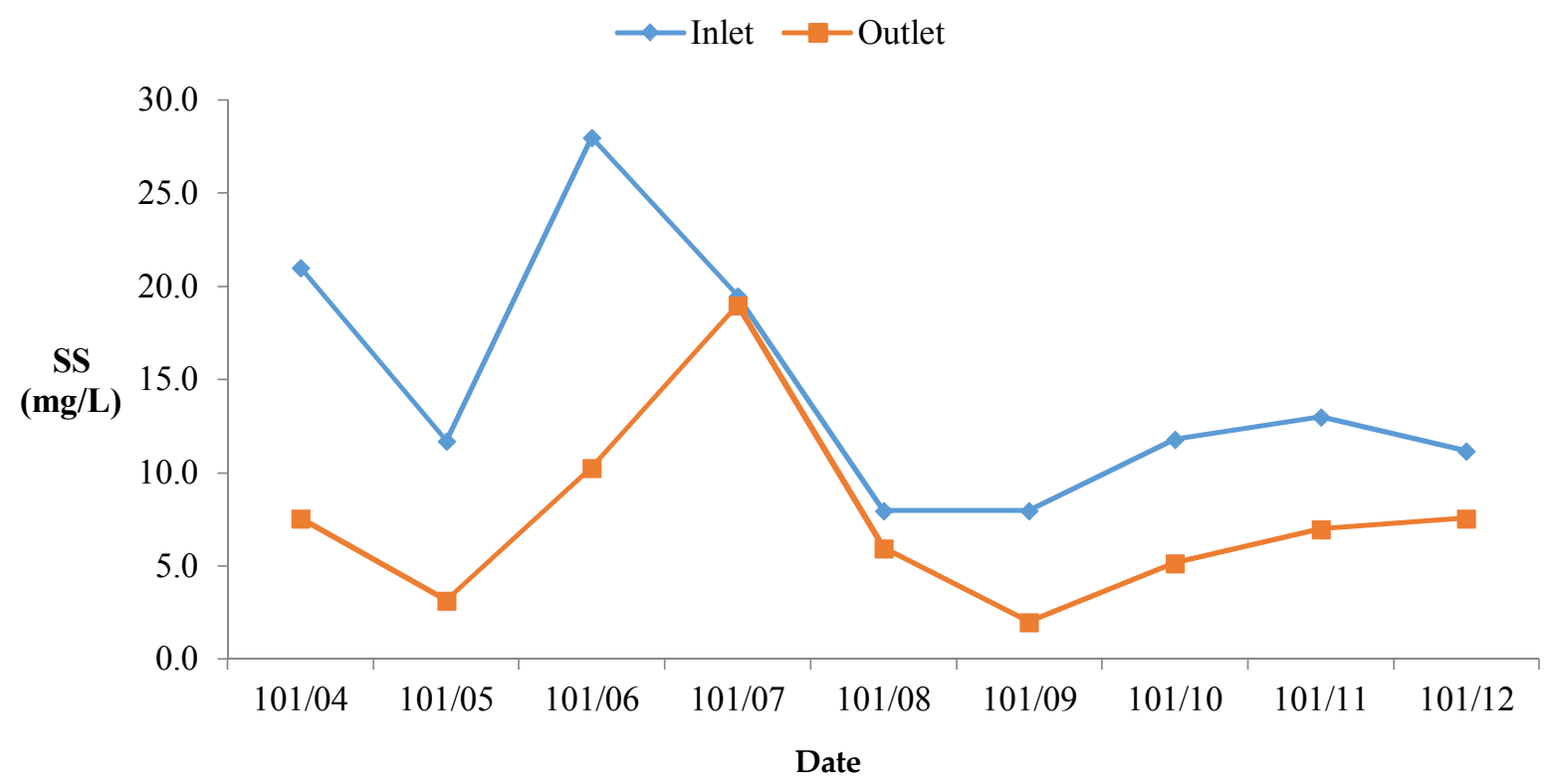

Figure 1a. SS concentration variation in inflow and outflow by using gravel contact oxygen treatment.

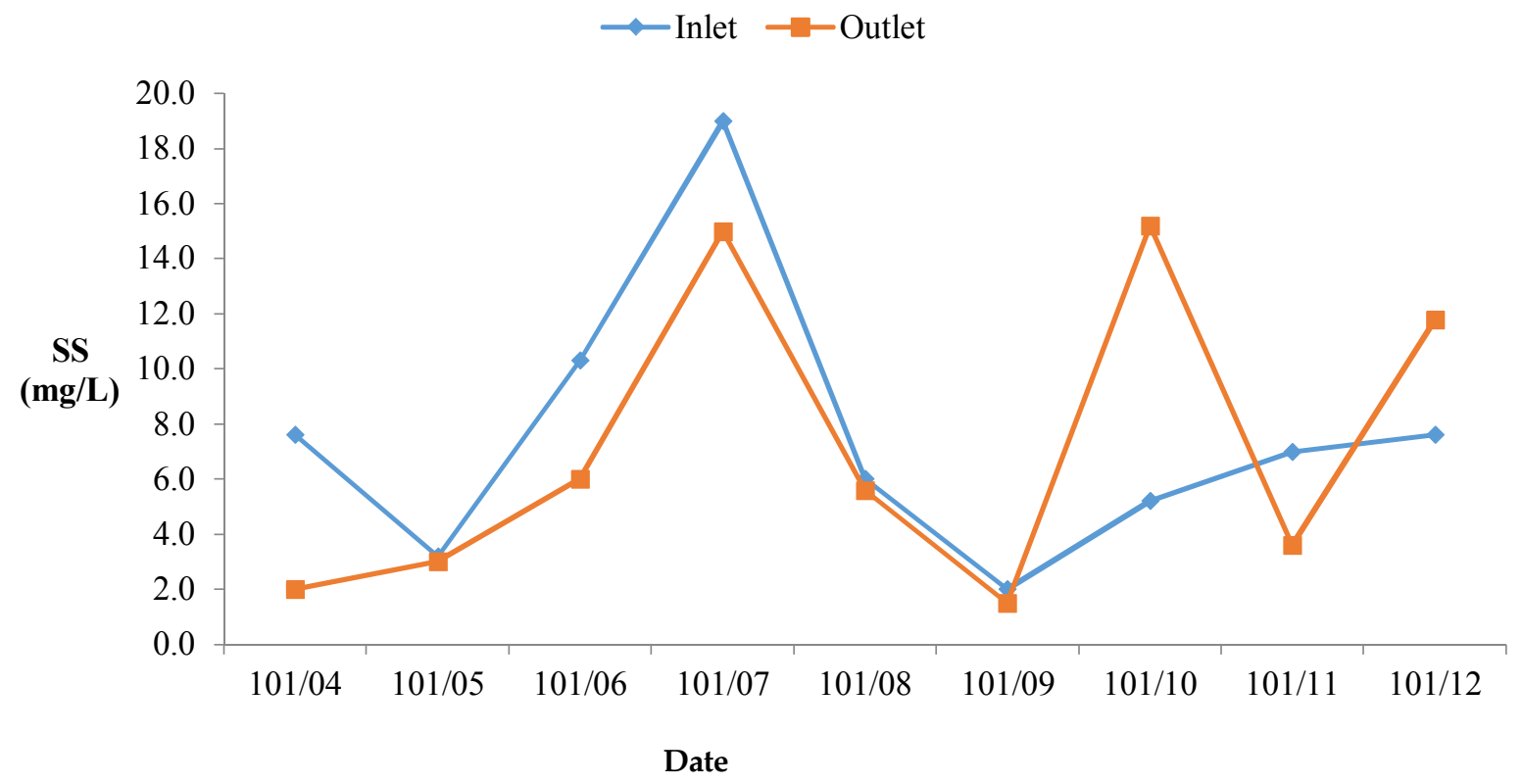

Figure 1b. SS concentration variation in inflow and outflow via the constructed wetland method. 


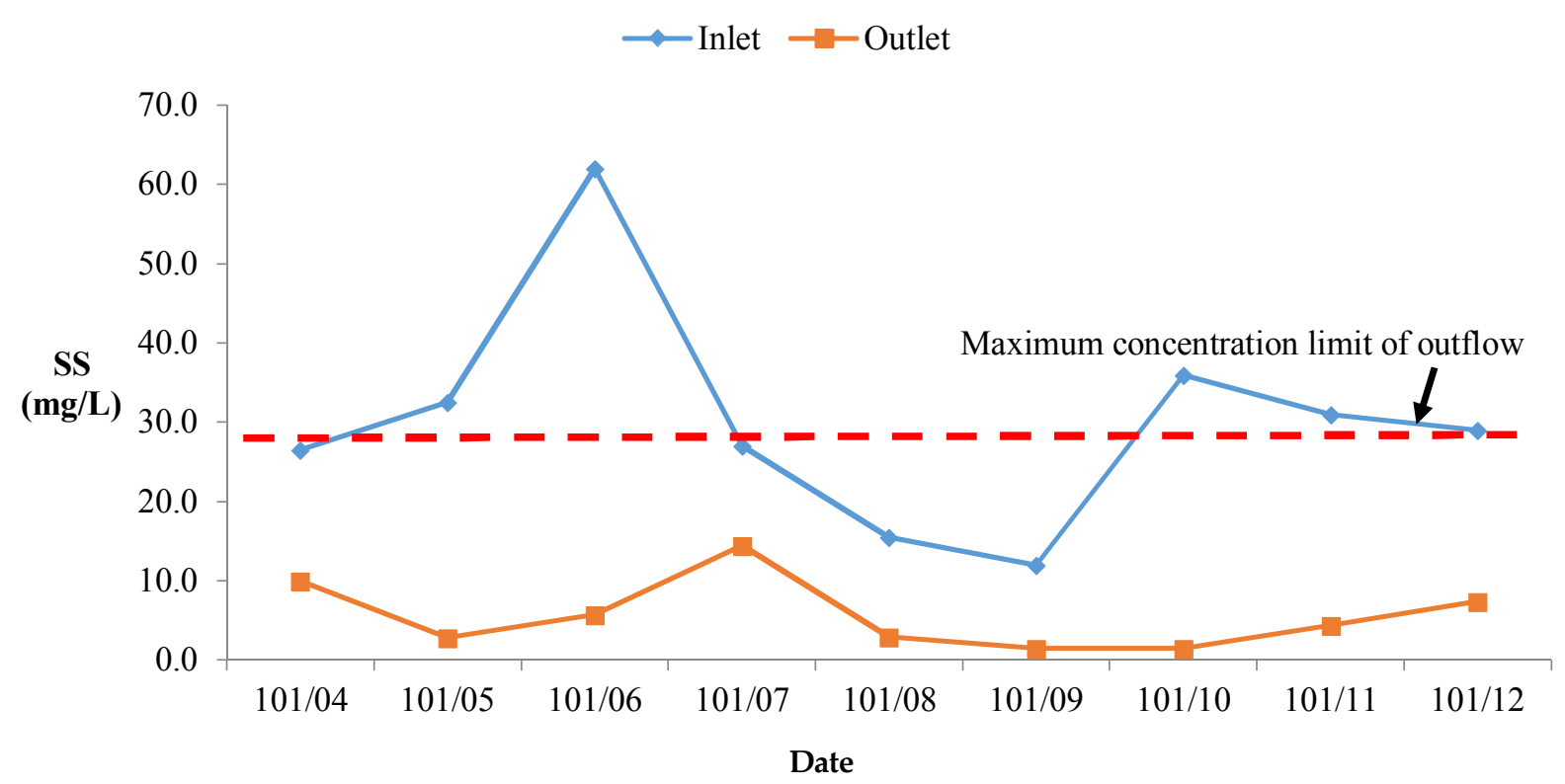

Figure 1c. SS concentration variation in inflow and outflow in the combined system of gravel contact oxygen treatment and the constructed wetland method.

\subsection{Removal Efficiency of $B O D$}

The removal efficiency of the BOD was $-14-54 \%$ using gravel contact oxidation treatment, as shown in Figures $2 \mathrm{a}$ and $2 \mathrm{~b}$. Figure $2 \mathrm{~b}$ shows that the BOD concentration in May increased from 3.9 to $5.6 \mathrm{mg} / \mathrm{L}$, and the removal efficiency of the BOD was similar using gravel contact oxidation treatment and the constructed wetland method. The BOD of the final outflow showed concentrations of $1.6-6.5 \mathrm{mg} / \mathrm{L}$, and these results were stable and matched BOD standards. The proper BOD concentration was less than $10 \mathrm{mg} / \mathrm{L}$. Figure 2c depicts that BOD concentrations of outflow in the combined system were lower than the maximum concentration limit of outflow, where the maximum concentration limit was $17 \mathrm{mg} / \mathrm{L}$, after gravel contact oxygen treatment and the constructed wetland method.

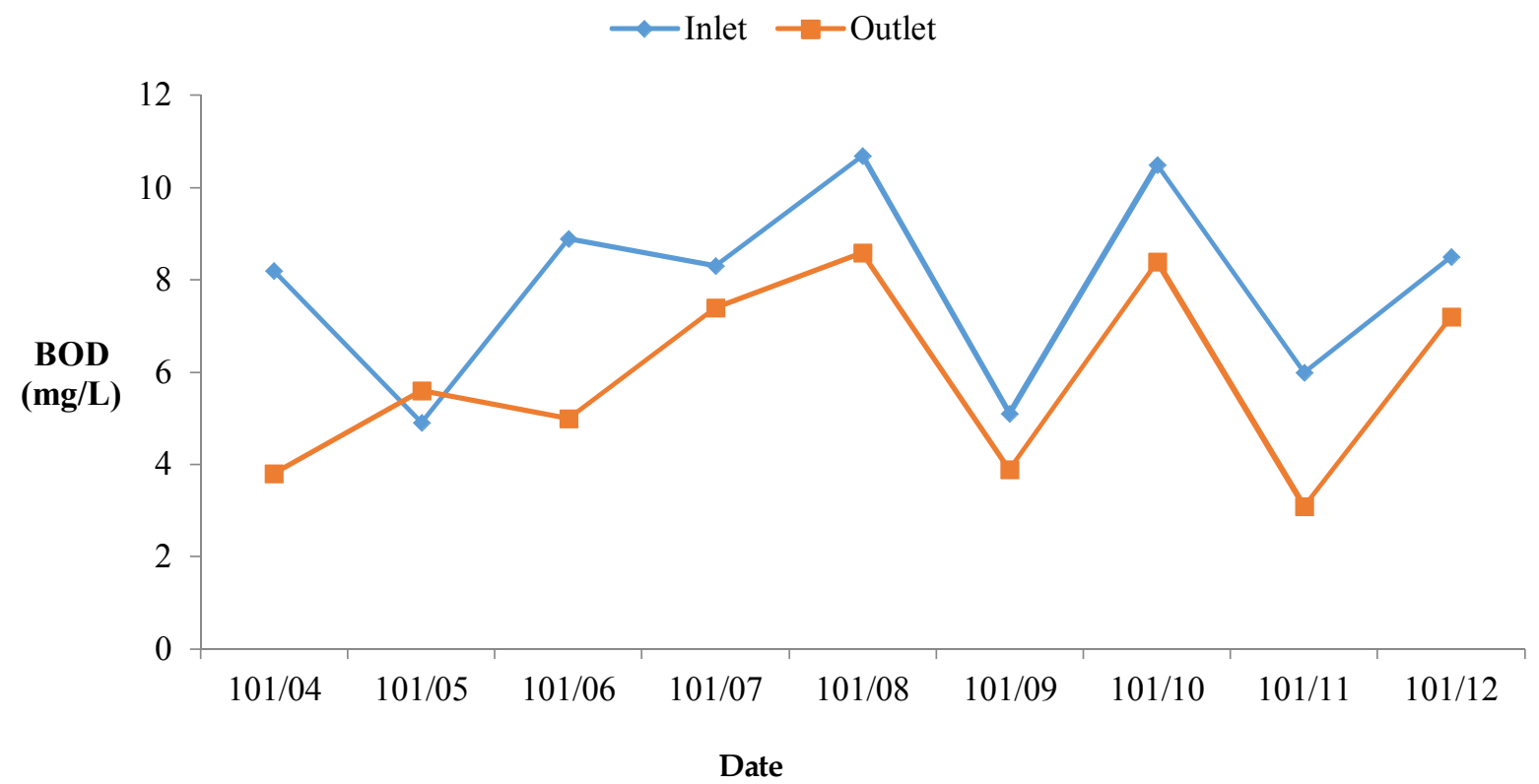

Figure 2a. BOD concentration variation in inflow and outflow by using gravel contact oxygen treatment. 


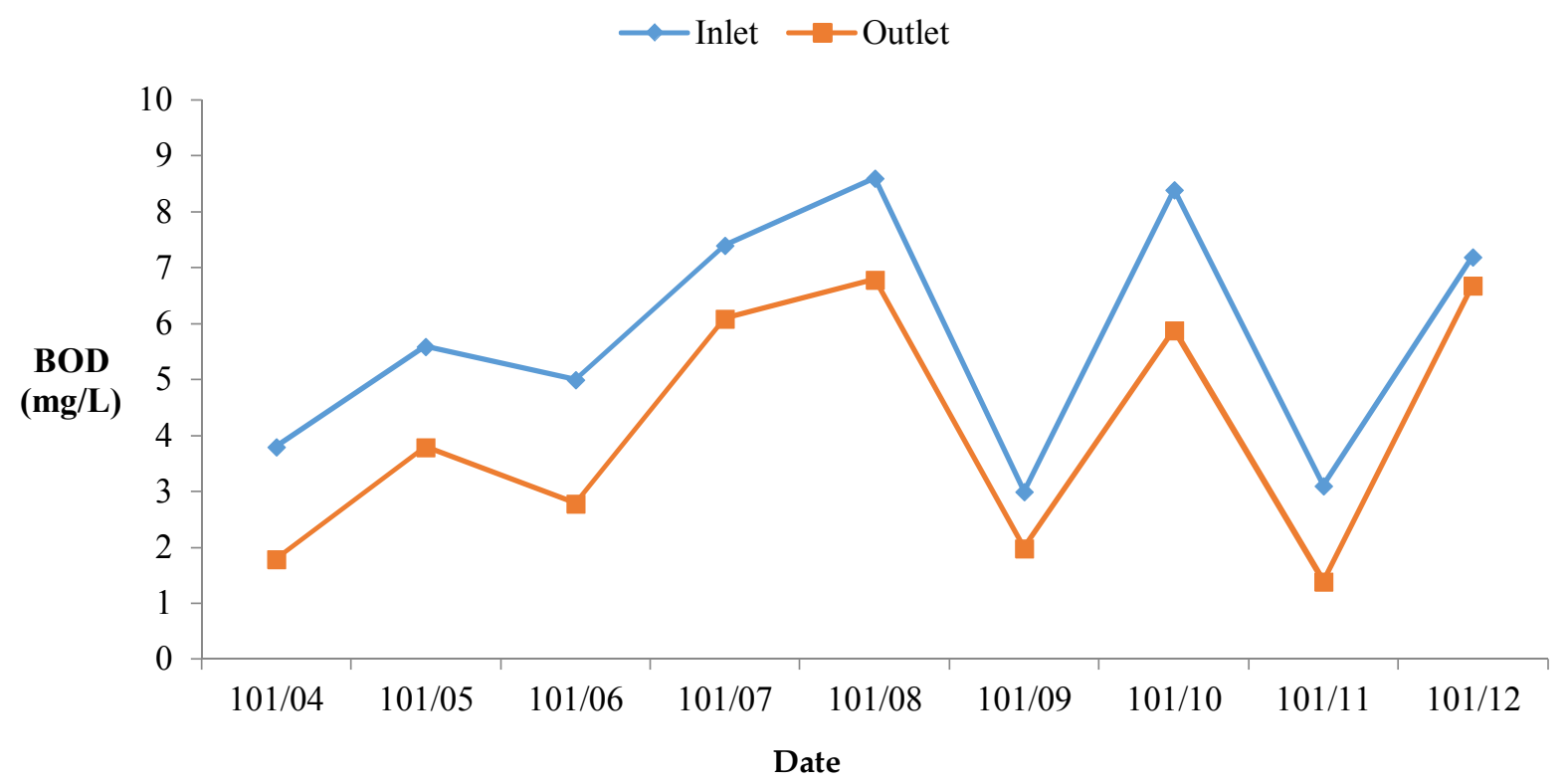

Figure $2 \mathbf{b}$. BOD concentration variation in inflow and outflow via the constructed wetland method.

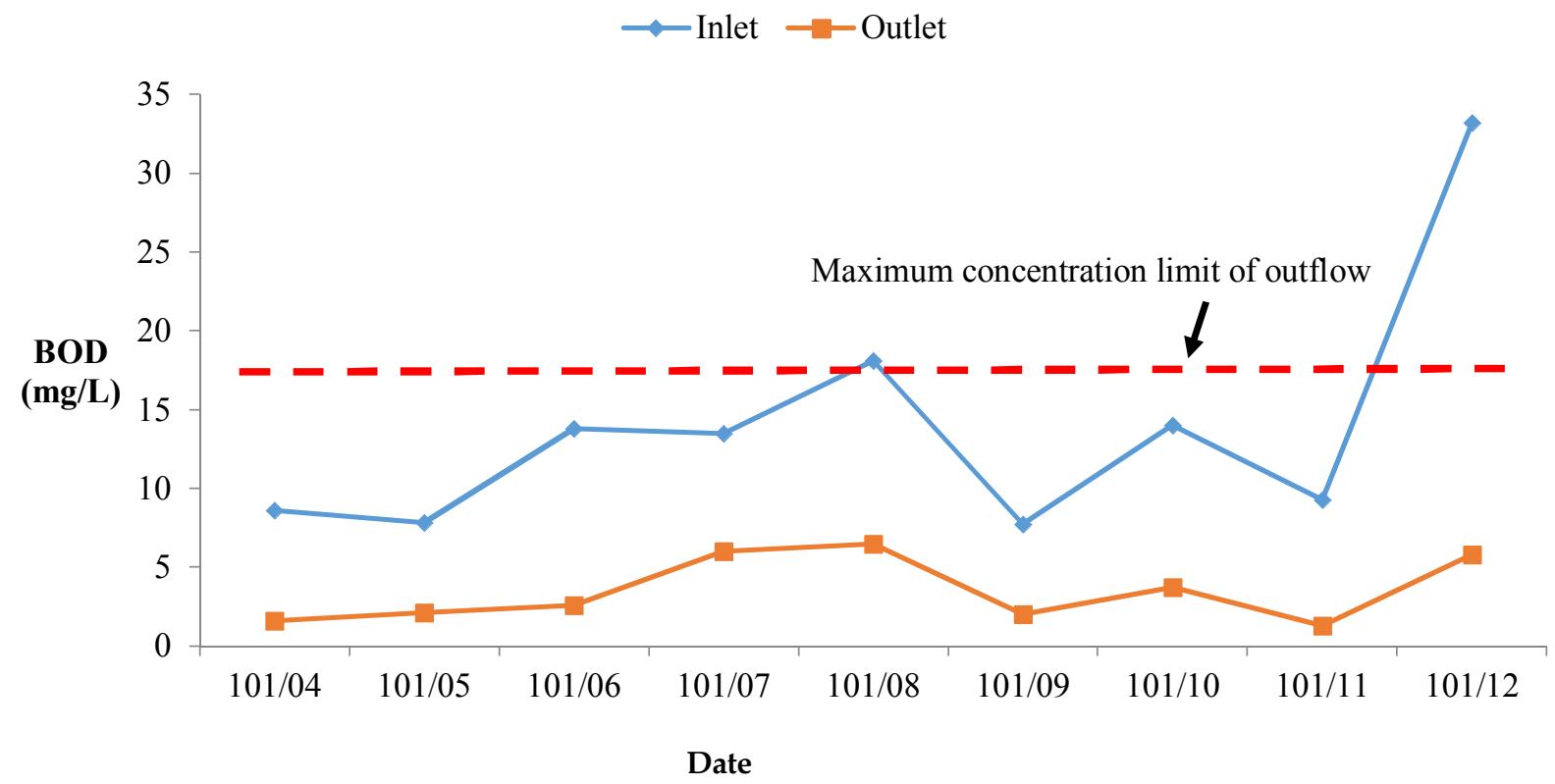

Figure 2c. BOD concentration variation in inflow and outflow in the combined system of gravel contact oxygen treatment and the constructed wetland method.

\subsection{Removal Efficiency of $T N$}

Figure 3a illustrates that the removal efficiency of TN was $17-74 \%$ via gravel contact oxidation treatment, and Figure $3 \mathrm{~b}$ depicts that the removal efficiency of TN was $2-67 \%$ by the constructed wetland method. The removal efficiency of $\mathrm{TN}$ in the combined system was $57-88 \%$. Although these removal efficiencies of $\mathrm{TN}$ in both June and November did not exceed $60 \%$ using gravel contact oxidation treatment or the constructed wetland method, TN concentration of outflows in June and November were 3.3 and $3.5 \mathrm{mg} / \mathrm{L}$, respectively. Both of those values are stable and less than $5 \mathrm{mg} / \mathrm{L}$. Figure $3 \mathrm{c}$ illustrates the TN concentration variation in inflow and outflow in the combined system, where the maximum concentration limit of the outflow was $7 \mathrm{mg} / \mathrm{L}$, and most TN concentrations were lower than the maximum concentration limit, excepting the values in April and 
June. Although approximately $63 \%$ of TN in April can be eliminated, the TN concentration in April was the maximum value, implying that the TN concentration of outflow cannot be lower than the maximum concentration limit due to a higher loading of pollution treatment. Furthermore, there was roughly $63 \%$ of TN in June, and the TN concentration in June is the second-largest value. As a result, the loading of pollution treatment was close to $60 \%$, and the TN removal efficiency of the combined system could reach close to $60 \%$.

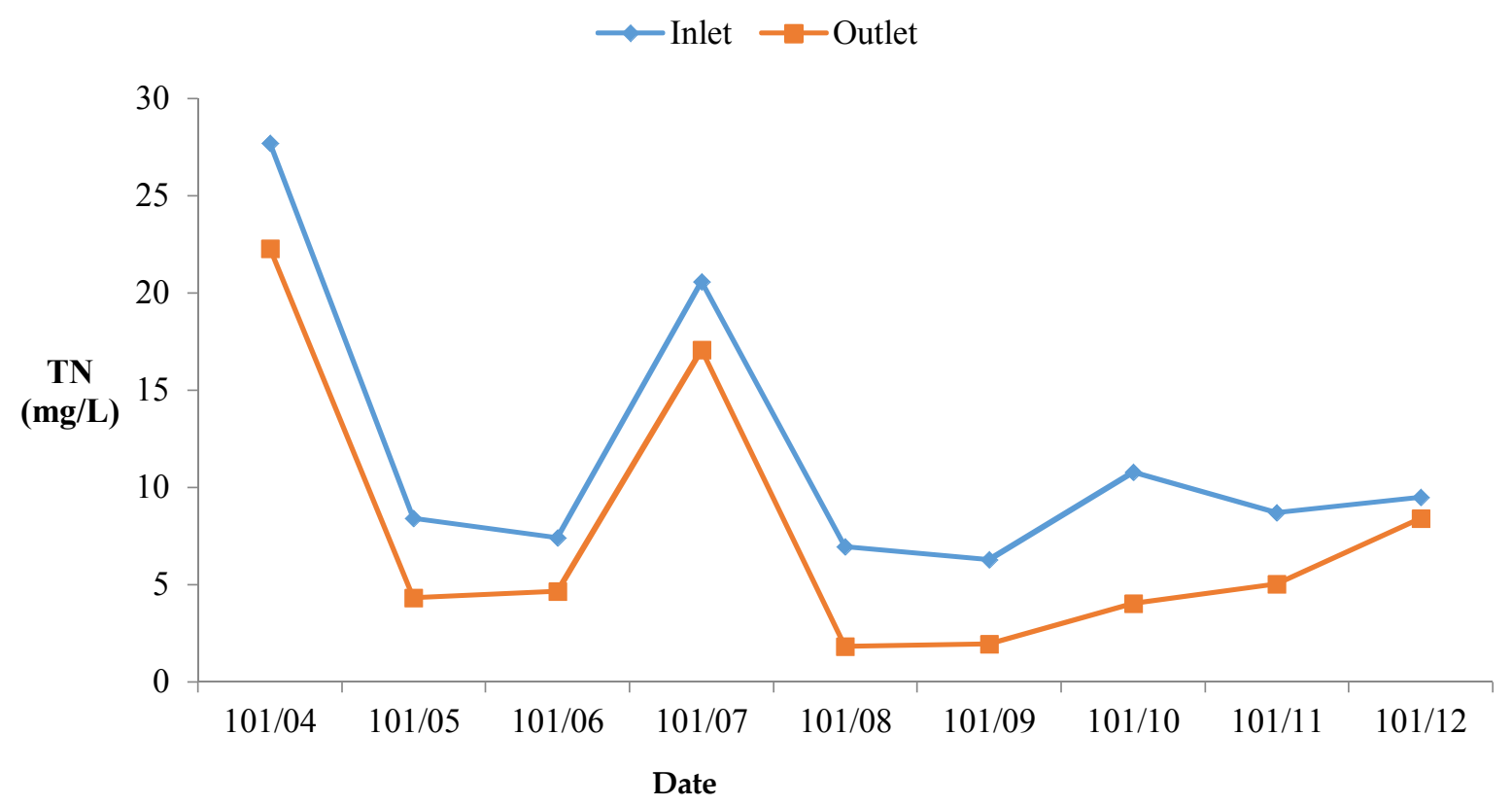

Figure 3a. TN concentration variation in inflow and outflow by using gravel contact oxygen treatment.

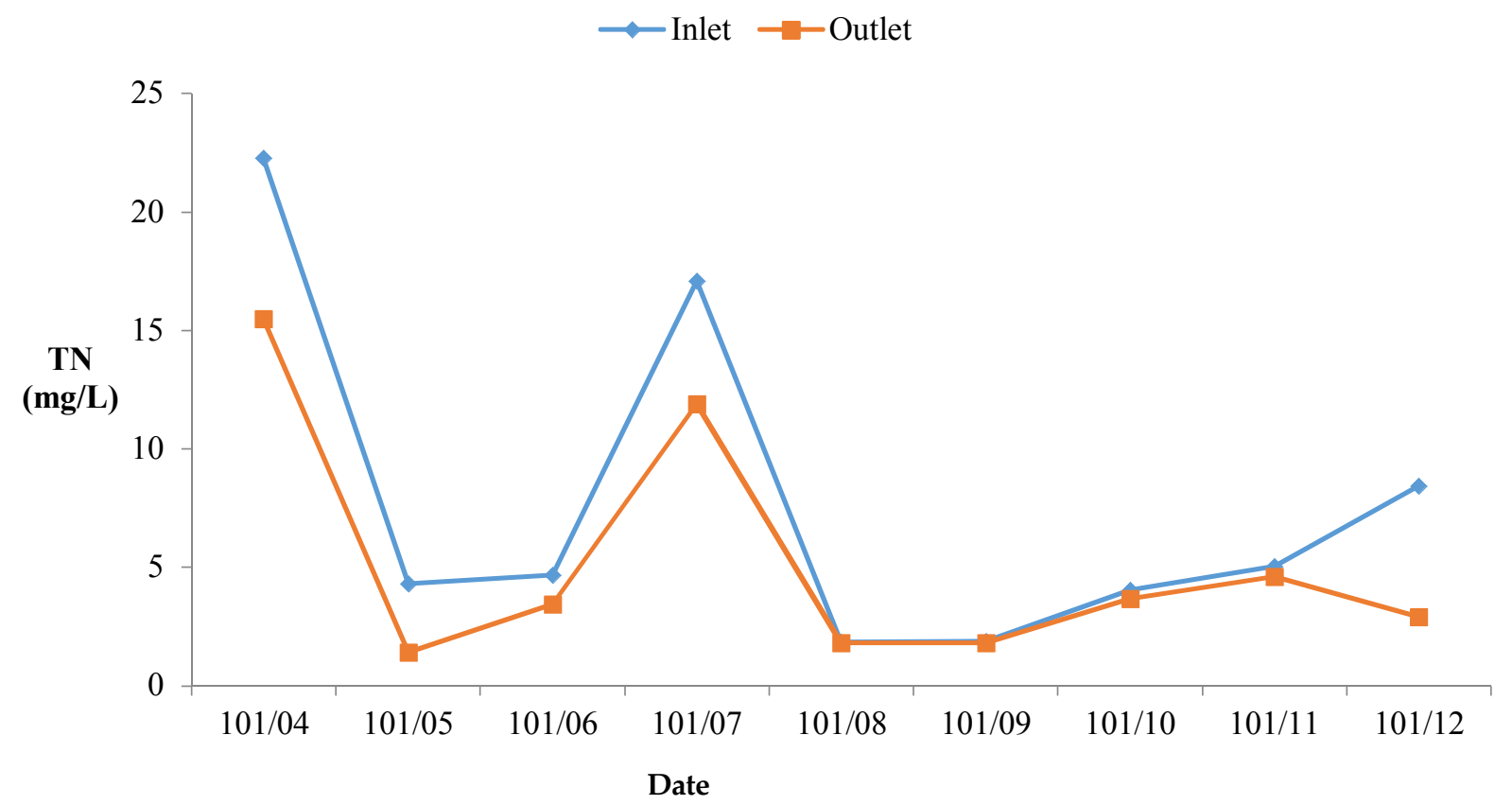

Figure $3 \mathbf{b}$. TN concentration variation in inflow and outflow via the constructed wetland method. 


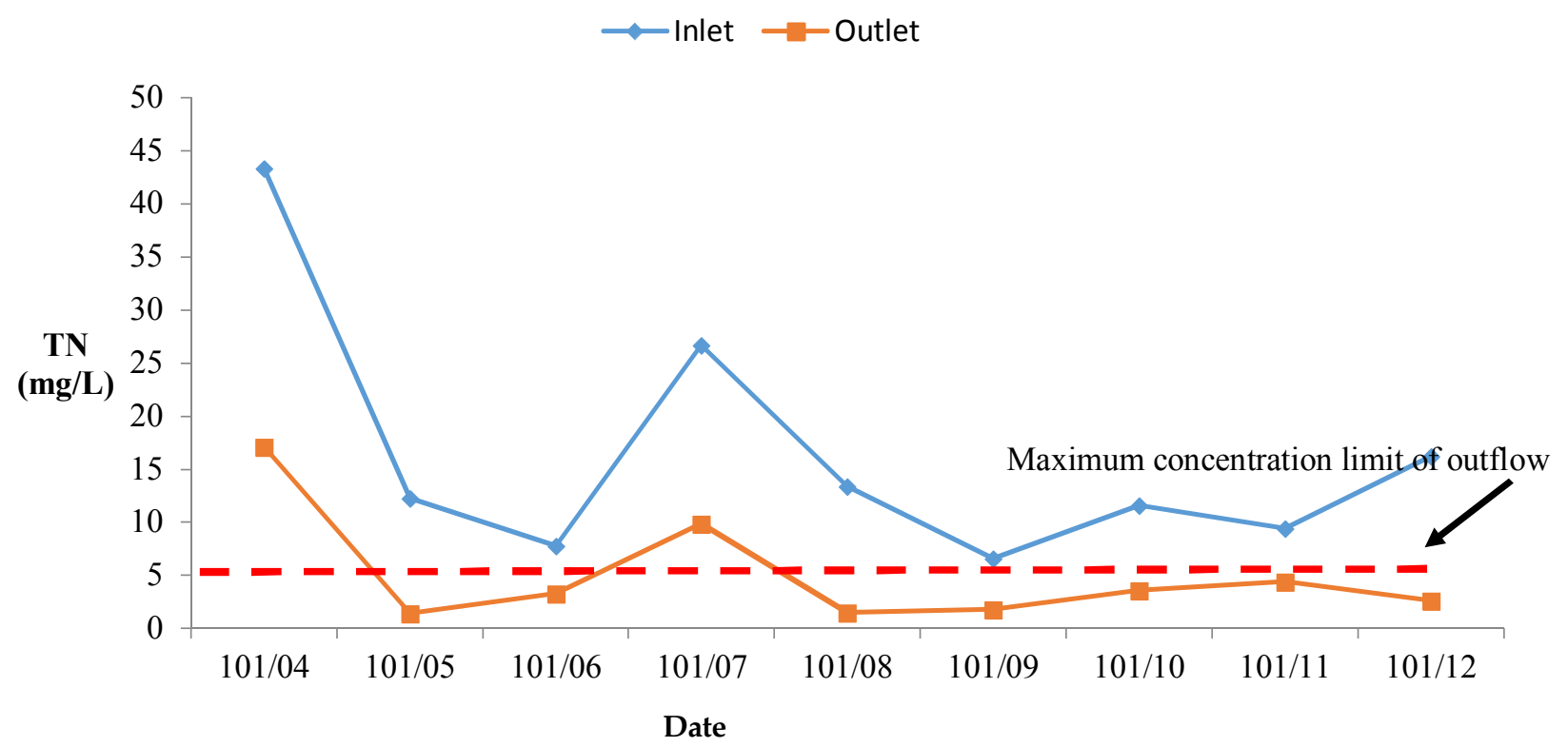

Figure 3c. TN concentration variation in inflow and outflow in the combined system of gravel contact oxygen treatment and the constructed wetland method.

\subsection{Removal Efficiency of TP}

Phosphate is a nutrient of growth for microorganisms and algae, and the demand dose of phosphate as a nutrient source is only rated as $1 / 100$ of a carbohydrate source. Moreover, Figures $4 \mathrm{a}$ and $4 \mathrm{~b}$ show that the TP concentration of inflow was $2.6 \mathrm{mg} / \mathrm{L}$, and the TP concentration of outflow was $1.4 \mathrm{mg} / \mathrm{L}$, the maximum values of all inflow and outflow values, respectively. The removal efficiency of TP in the combined system was $12-82 \%$, as shown in Figure 4c, and the following steps resulted in high removal efficiency values. Digestion and adsorption occurred actively in the growth of microorganisms and algae, and the removal efficiency of TP was also altered by the traits of sand samples. According to Akratos and Tsihrintzis [29], natural sands consist of $\mathrm{Fe}, \mathrm{Al}$, and $\mathrm{Ca}$ components. The components of natural sands were different in plastic filter samples, and phosphate ions carried electric charges to be adsorbed by positively charged ions, $\mathrm{Fe}, \mathrm{Al}$, and $\mathrm{Ca}$. Furthermore, the regular disposal of spoil helped eliminate pollution.

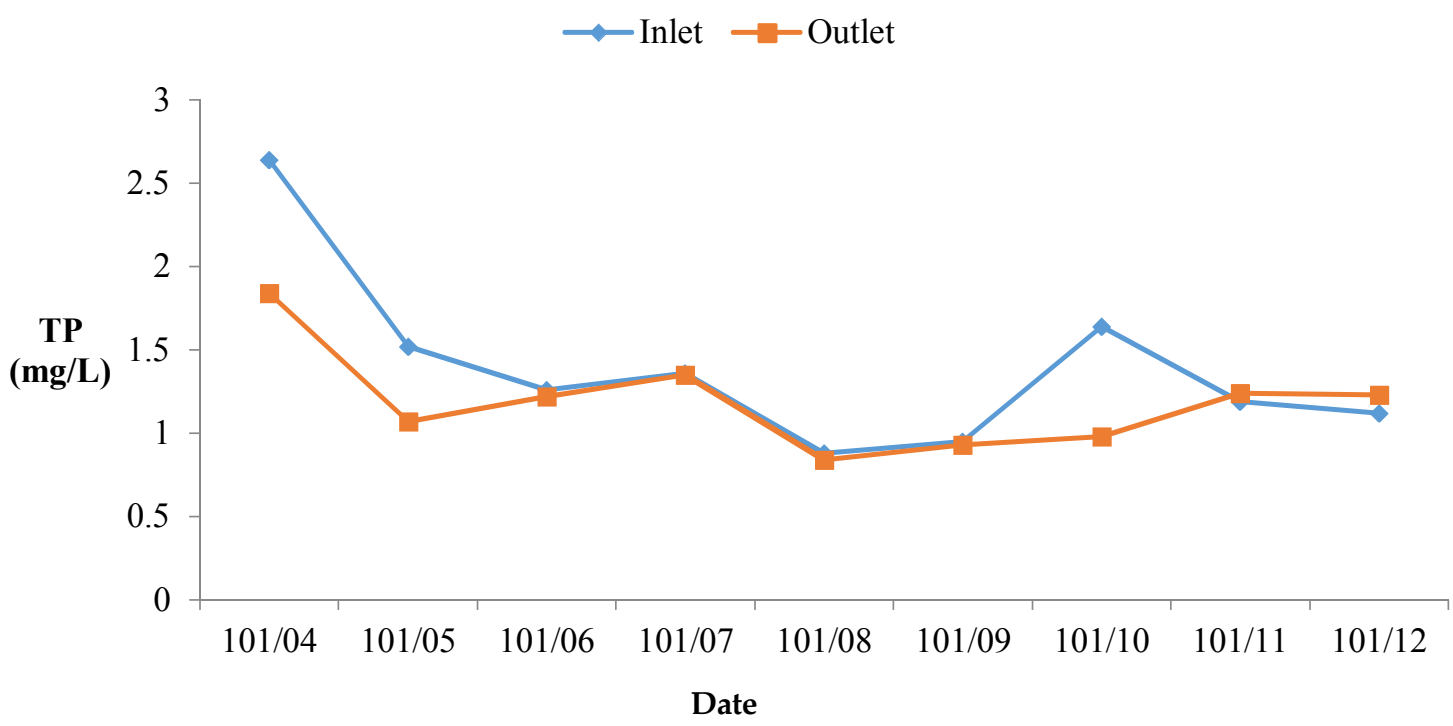

Figure 4a. TP concentration variation in inflow and outflow by using gravel contact oxygen treatment. 


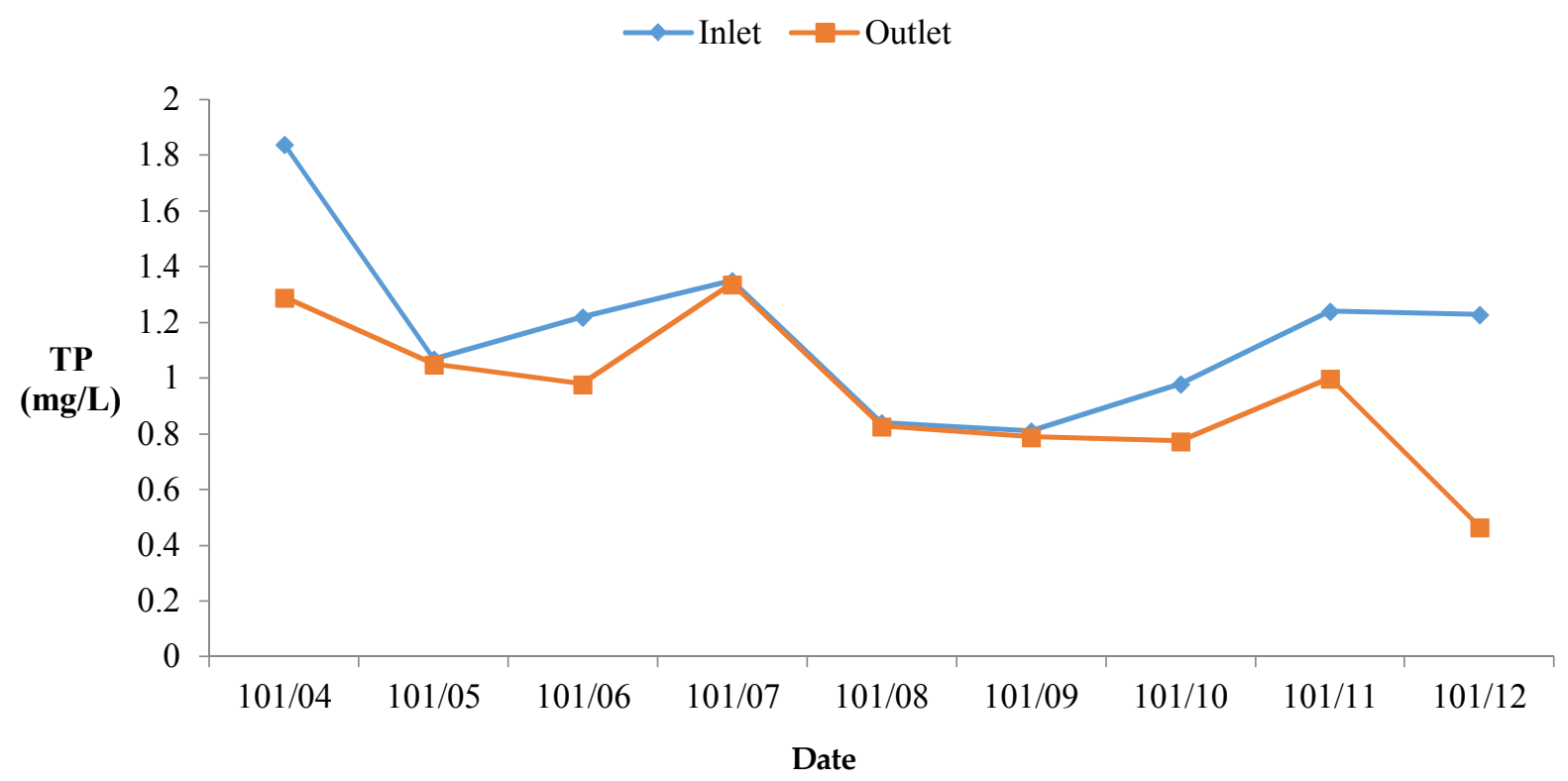

Figure $4 \mathrm{~b}$. TP concentration variation in inflow and outflow via the constructed wetland method.

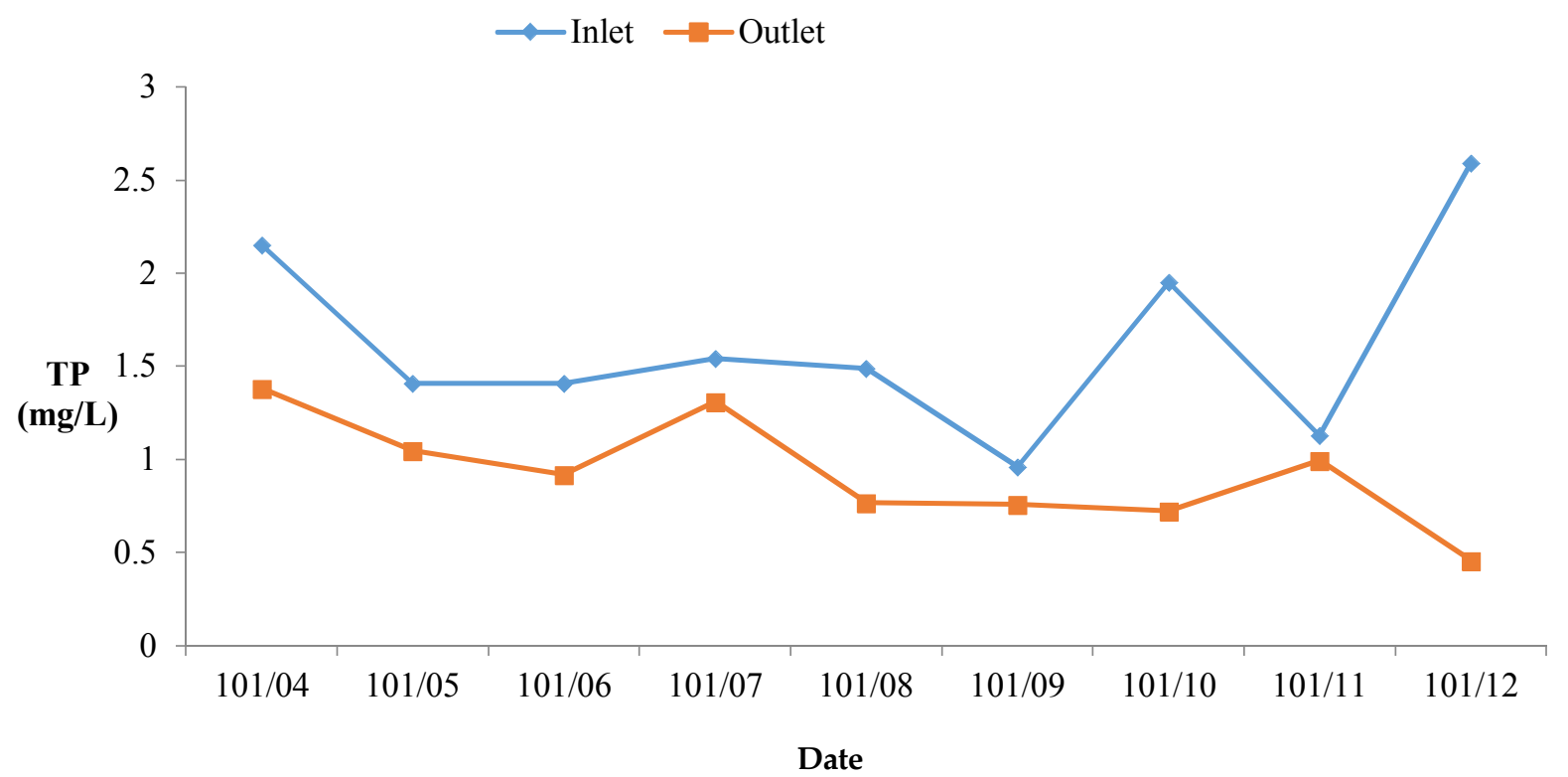

Figure 4c. TP concentration variation in inflow and outflow in the combined system of gravel contact oxygen treatment and the constructed wetland method.

However, the effect of reverse flushing via gravel did not obviously accompany the operational time of the gravel contact oxidation treatment and the constructed wetland method, and the sludge deposit thus worked to decrease removal efficiency. This effect is an assumption on which the reduction of the removal efficiency of TP is based. The adsorption of bottom soil and the digestion of aquatic plants for growth in the constructed wetland also enhanced the removal efficiency of TP.

\subsection{Removal Efficiency of $\mathrm{NH}_{3}-\mathrm{N}$}

Figure 5a shows that the maximum $\mathrm{NH}_{3}-\mathrm{N}$ concentration of inflow was $13.9 \mathrm{mg} / \mathrm{L}$ using gravel contact oxidation treatment, and the removal efficiency of $\mathrm{NH}_{3}-\mathrm{N}$ reached a maximum value of $98 \%$. Most $\mathrm{NH}_{3}-\mathrm{N}$ concentrations during the whole year were lower despite higher $\mathrm{NH}_{3}-\mathrm{N}$ concentrations in April and July, as shown in Figure 5b. Figure 5b depicts that the removal 
efficiency of $\mathrm{NH}_{3}-\mathrm{N}$ reached a maximum value of $92 \%$ using the constructed wetland method. Although the $\mathrm{NH}_{3}-\mathrm{N}$ concentration in May was lower than $0.04 \mathrm{mg} / \mathrm{L}$ and the $\mathrm{NH}_{3}-\mathrm{N}$ concentration in August was not detected (ND), the combined removal efficiency reached $100 \%$, as illustrated in Figure 5c. The proper reason of $100 \%$ removal efficiency was that a lot of rains diluted the concentration of wastewater due to the raining season during August to December.

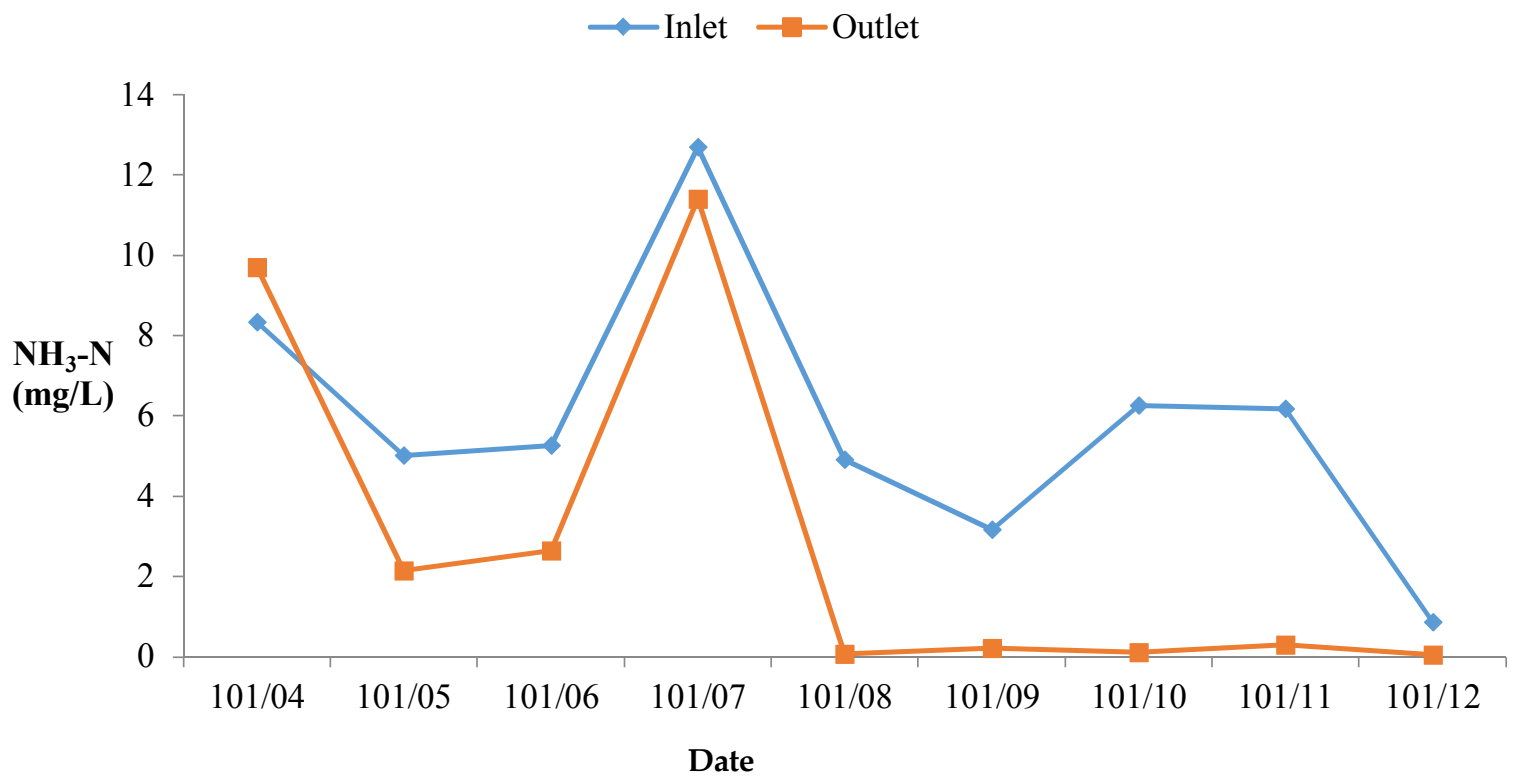

Figure 5 a. $\mathrm{NH}_{3}-\mathrm{N}$ concentration variation in inflow and outflow by using gravel contact oxygen treatment.

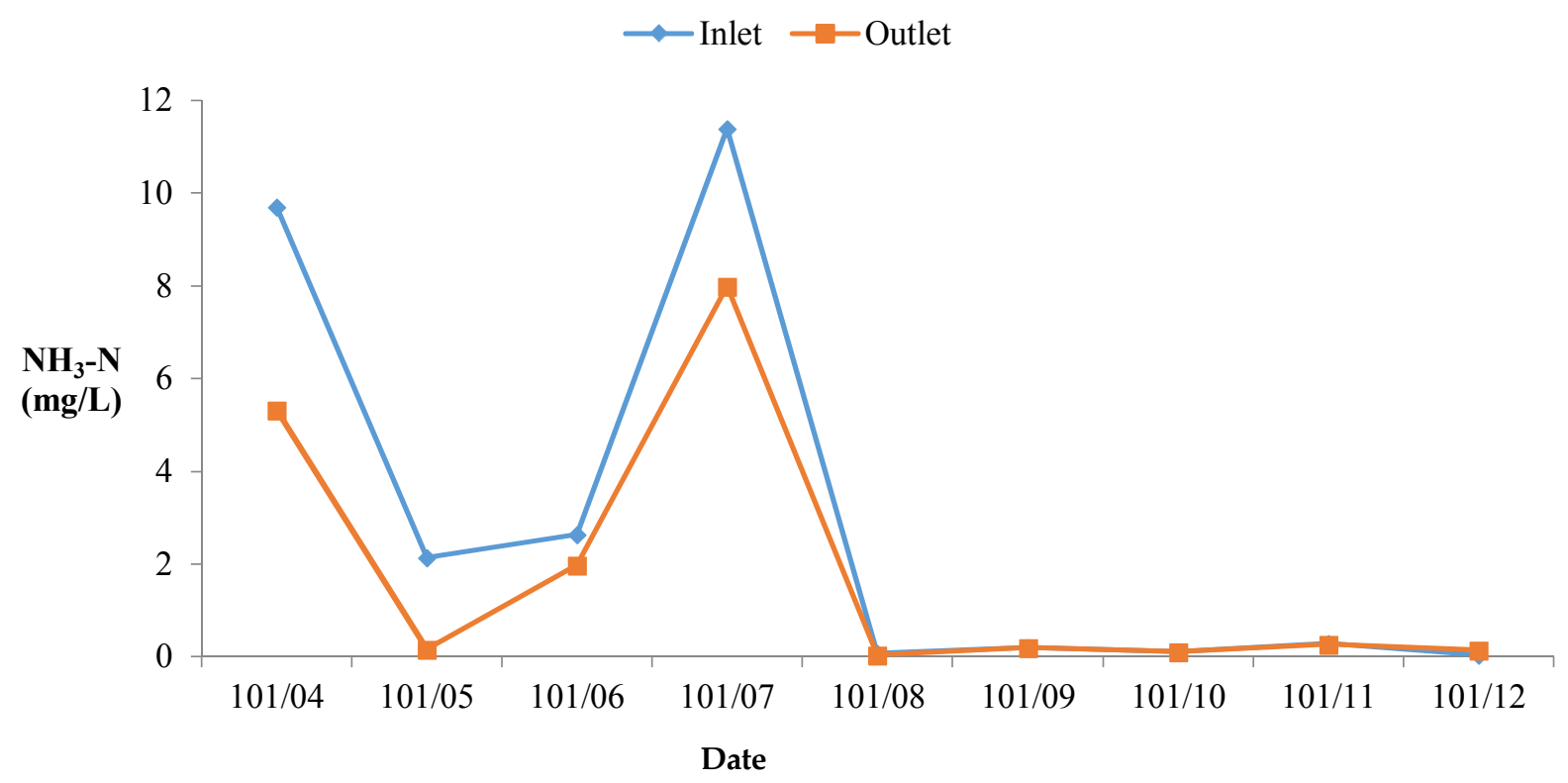

Figure $5 \mathbf{b} . \mathrm{NH}_{3}-\mathrm{N}$ concentration variation in inflow and outflow via the constructed wetland method. 


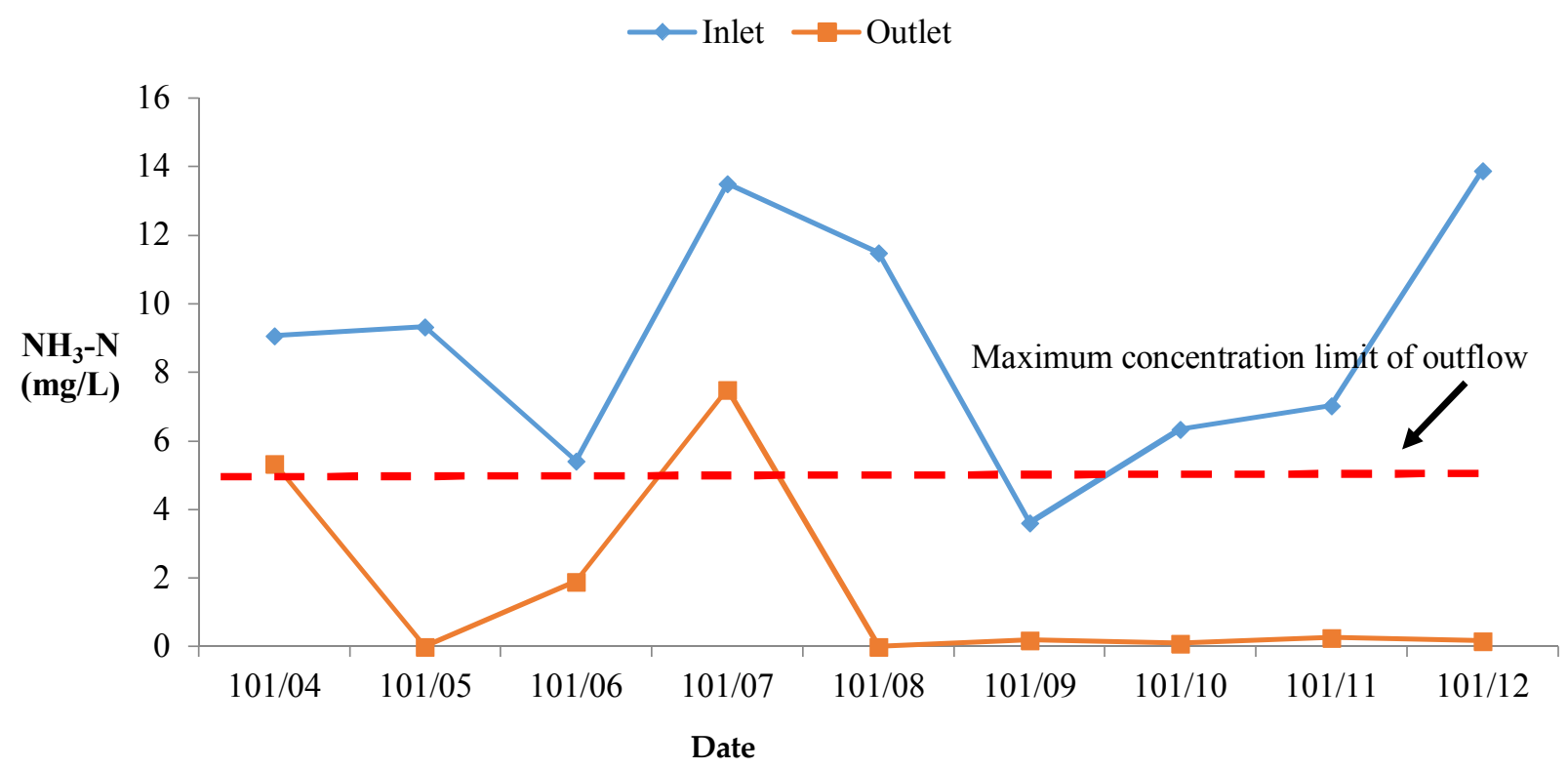

Figure 5 c. $\mathrm{NH}_{3}-\mathrm{N}$ concentration variation in inflow and outflow in the combined system of gravel contact oxygen treatment and the constructed wetland method.

\subsection{Summary of Pollution Control and Analysis of the River Pollution Index of the Inflow and Outflow}

A summary of changes due to gravel contact oxidation treatment and the constructed wetland method shows that the removal efficiencies of $\mathrm{SS}, \mathrm{BOD}, \mathrm{TN}, \mathrm{TP}$, and $\mathrm{NH}_{3}-\mathrm{N}$ can all reach maximum values if the inflow concentration is relatively high. However, some inflow concentrations are lower, resulting in an unstable removal efficiency and unclear treatment efficiency. Improved removal efficiency occurred with the loading of high-concentration pollution. The river pollution index (RPI) is a comprehensive index for the evaluation of river quality, which is currently used by the EPA to estimate the degree of river pollution. There are four parameters that comprise the RPI: oxygen demand (DO), biochemical oxygen demand (BOD), suspended solid (SS), and ammonia nitrogen $\left(\mathrm{NH}_{3}-\mathrm{N}\right)$. The evaluation method is indicated in Table 2 . The value of $\mathrm{RPI}$ is $(\Sigma \mathrm{Ni}) / 4$, where Ni represents the degree of different pollutions. The RPI value ranges from 1 to 10 , and four degrees of water pollution are involved to differentiate the degree of pollution. This study adopted wastewater from the outflow of the Yangzi-Cuo River, Ci-Tong Jiao, as the test sample, and the water was returned to the river after gravel contact oxidation treatment and the constructed wetland method. The RPI index was used to evaluate the purification performance of wastewater. Based on the data collection regarding inflow and outflow of DO, BOD, SS, and $\mathrm{NH}_{3}-\mathrm{N}$ from 101/04-101/12, the resulting RPI indexes are presented in Table 2. It can be concluded that the water quality improved after these wastewater treatments. There are four levels pollution of RPI indexes, including little, slight, medium, and serious pollution, and the corresponding values of these pollution is located at the regions of below $2.0 \mathrm{mg} / \mathrm{L}, 2.0-3.0 \mathrm{mg} / \mathrm{L}, 3.0-6.0 \mathrm{mg} / \mathrm{L}$, and above 6.0 $\mathrm{mg} / \mathrm{L}$. The original wastewater was classified as having serious pollution, and the post-treatment wastewater was classified as having slight pollution or medium pollution, as shown in Figure 6. The water quality in July could not reach the level of slight pollution or little pollution, because many insecticides were applied to eliminate snails in farms, resulting in residual insecticides flowing into the Yangzi-Cuo River, Ci-Tong Jiao, polluting the water. Figure 7 shows the wastewater variation in the upstream and downstream outflow. The water quality of the downstream outflow appears to have improved after wastewater treatment. Furthermore, the original inflow with an RPI index indicating serious pollution changed to an outflow with RPI indexes of slight pollution and medium pollution. 
Table 1. Specifications on the design of the constructed wetland.

\begin{tabular}{ll}
\hline \multicolumn{1}{c}{ Items } & \multicolumn{1}{c}{ Conditions } \\
\hline Designed method & Gravel contact oxidation and surface flow constructed wetland \\
Area & a. Total base area: 9000 square meter. \\
Inflow source & b. Water purification treatment area: 730 square meter. \\
Treatment location & Household wastewater in Ci-Tong Jiao, Changhua County. \\
Inflow way & Land numbers of $1-4$ and $1-5$ in Ci-Tong Jiao, Changhua County. \\
Treatment capacity & Coordinates position: $(23.070949,120.505699)$. \\
Inflow concentration & Gravity type and pumping motor diversions \\
Outflow concentration & 2000 cubic meters per day $(\mathrm{CMD})$ \\
Removal capacity & BOD5: $50 \mathrm{mg} / \mathrm{L} ; \mathrm{NH}_{3}-\mathrm{N}: 80 \mathrm{mg} / \mathrm{L} ; \mathrm{SS}: 50 \mathrm{mg} / \mathrm{L}$ \\
Removal efficiency & BOD5: $20 \mathrm{mg} / \mathrm{L} ; \mathrm{NH}_{3}-\mathrm{N}: 48 \mathrm{mg} / \mathrm{L} ; \mathrm{SS}: 20 \mathrm{mg} / \mathrm{L}$ \\
HRT & BOD5: $20 \mathrm{Kg} / \mathrm{D} ; \mathrm{NH}-\mathrm{N}<5 \mathrm{Kg} / \mathrm{D} ; \mathrm{SS}<20 \mathrm{Kg} / \mathrm{D} ; \mathrm{TP}<5 \mathrm{Kg} / \mathrm{D}$ \\
Expectation of purified outflow concentration & BOD5: $60 \% ; \mathrm{NH} 3-\mathrm{N}: 40 \% ; \mathrm{SS}: 60 \% ; \mathrm{TP}: 60 \%$ \\
& 2.59 days \\
\hline
\end{tabular}

Table 2. Calculation of the river pollution index (RPI) and the degree of pollution on different items.

\begin{tabular}{ccccc}
\hline Item/Degree of Pollution & $\begin{array}{c}\text { Little } \\
\text { Pollution }\end{array}$ & $\begin{array}{c}\text { Slight } \\
\text { Pollution }\end{array}$ & $\begin{array}{c}\text { Medium } \\
\text { Pollution }\end{array}$ & $\begin{array}{c}\text { Serious } \\
\text { Pollution }\end{array}$ \\
\hline Oxygen demand $(\mathrm{mg} / \mathrm{L})$ & $>6.5$ & $3.6-6.5$ & $2.0-3.5$ & $<2.0$ \\
Biochemical oxygen demand $(\mathrm{mg} / \mathrm{L})$ & $<3.0$ & $3.0-3.9$ & $5.0-15$ & $>15$ \\
Suspended solid $(\mathrm{mg} / \mathrm{L})$ & $<20$ & $20-49$ & $50-100$ & $>100$ \\
Ammonia nitrogen $(\mathrm{mg} / \mathrm{L})$ & $<0.5$ & $0.5-0.99$ & $1.0-3.0$ & $>3.0$ \\
Point on degree of different & 1 & 3 & 6 & 10 \\
pollutions & & & $3.1-6.0$ & $>6.0$ \\
RPI value & $<2.0$ & $2.0-3.0$ & & \\
\hline
\end{tabular}

$\multimap$ RPI(Inlet) $\rightarrow$ RPI(Outlet)

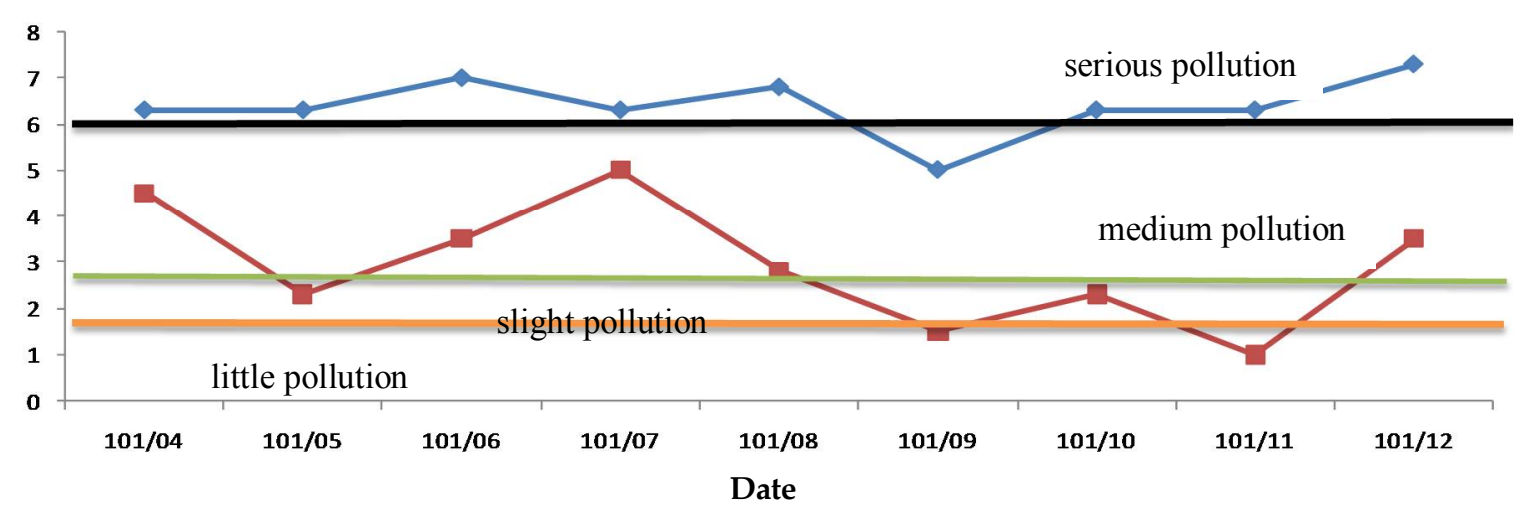

Figure 6. RPI values of inflow and outflow.

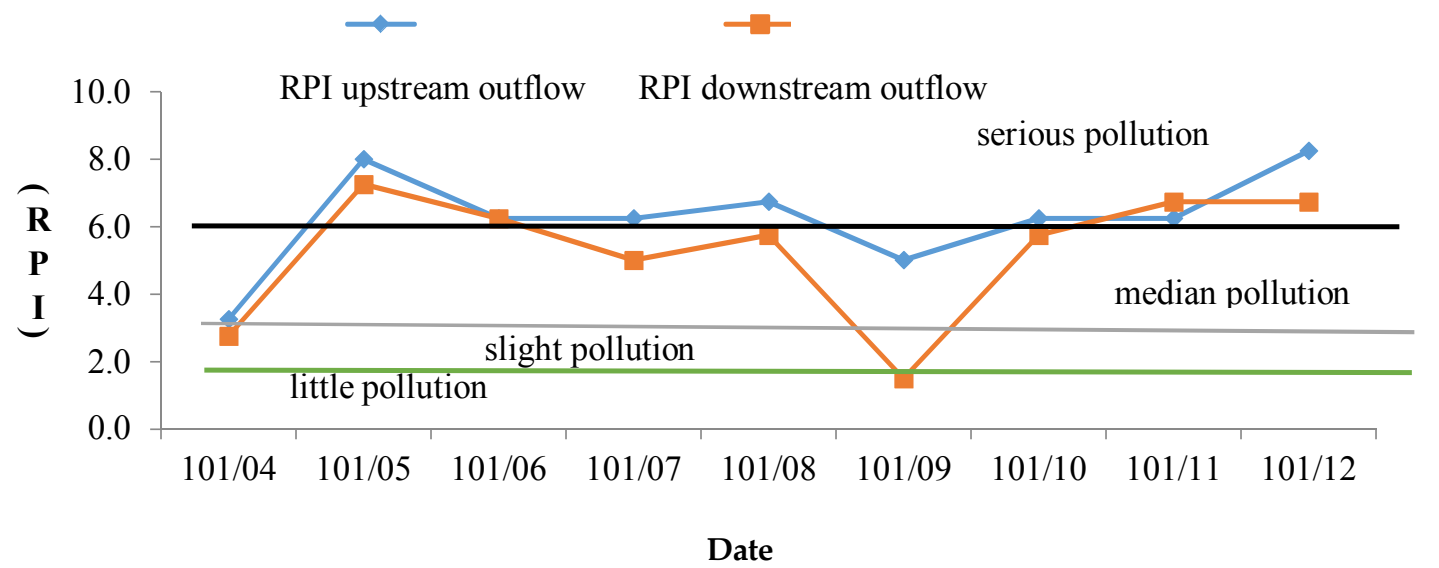

Figure 7. RPI values of upstream and downstream outflow. 


\section{Conclusions}

This case study focused on river quality enhancement in Changhua via cooperation with the Environmental Protection Bureau of Changhua County. This study presented the results of decreases in river pollution in the Yangzi-Cuo River, Ci-Tong Jiao, Changhua County, Taiwan, due to treatments of gravel contact oxidation and surface flow constructed wetlands. Gravel contact oxidation and surface flow constructed wetlands comprise ecology technology, aimed at using physical, chemical, and biological designs to eliminate river pollution via the mediums of soil, plant, water, and microorganisms from natural environments. Moreover, RPI reduction was applied to evaluate the efficiency of river quality enhancement. The upstream outflow belonged to serious pollution due to RPI value above $6 \mathrm{mg} / \mathrm{L}$, and downstream outflow turned to medium and slight pollution because of RPI values of 3-6 mg/L and 2-3 mg/L, respectively. Furthermore, initial values of $\mathrm{SS}, \mathrm{NH}_{3}-\mathrm{N}, \mathrm{TP}, \mathrm{TN}$, and $\mathrm{BOD}$ were found to be $10.0-26.7 \mathrm{mg} / \mathrm{L}, 0.9-14.0 \mathrm{mg} / \mathrm{L}, 1.2-14.1$ $\mathrm{mg} / \mathrm{L}, 11.1-18.2 \mathrm{mg} / \mathrm{L}$, and 0.5-3.6 mg/L, respectively, and final values of $\mathrm{SS}, \mathrm{NH}_{3}-\mathrm{N}, \mathrm{TP}, \mathrm{TN}$, and BOD were found to be $1.4-8.0 \mathrm{mg} / \mathrm{L}, 0.3-2.13 \mathrm{mg} / \mathrm{L}, 0.22-2.4 \mathrm{mg} / \mathrm{L}, 3.35-5.53 \mathrm{mg} / \mathrm{L}$, and $0.5-7.4 \mathrm{mg} / \mathrm{L}$ after purification treatment by ecology technology, respectively. The efficiencies of pollution elimination on $\mathrm{SS}, \mathrm{NH}_{3}-\mathrm{N}, \mathrm{TP}, \mathrm{TN}$, and BOD were $24.2-93.1 \%$, 58.3-86.2\%, 5.2-85.0\%, 59.4-77.2\%, and $46.3-76.4 \%$, respectively. Thus, this study indicates a substantial reduction in river pollution using combinations of gravel contact oxidation and surface flow constructed wetlands, and almost outlet values of those five factors do not exceed the maximum concentration limits of each pollutants' regulation, respectively. As a result, most efficiencies of pollution elimination are above $76 \%$. Moreover, water quality of downstream outflow tends to medium and slight pollution after application of ecological engineering methods. Therefore, the study presents great results on the purification efficiency of Yangzi-Cuo River by using ecological engineering methods.

Author Contributions: For research articles with several authors, including Chen-Chiang Chou, Wei-Ting Chen, and Yung-Pin Tsai, Mr. Chou and his team (River Long Environment Engineering Cooperation) worked on experimental tests and data collection. Dr. Chen wrote and elaborated this study based on the experimental tests and data collection from Mr. Chou and his team. Moreover, Dr. Tsai revised and summarized this study before submission of this MS to the journal of Applied Science.

Funding: This research received no external funding.

Conflicts of Interest: The authors declare no conflicts of interest.

\section{Reference}

1. Ichinari, T.; Ohtsubo, A.; Ozawa, T.; Hasegawa, K.; Teduka, K.; Oguchi, T.; Kiso, Y. Wastewater treatment performance and sludge reduction properties of a household wastewater treatment system combined with an aerobic sludge digestion unit. Process Biochem. 2008, 43, 722-728.

2. Li, Z.; Li, M.; Liu, X.; Ma, Y.; Wu, M. Identification of priority compounds in groundwater recharge of. China. Sci. Total Environ. 2014, 493, 481-486.

3. Daude, D.; Stephenson, T. Cost-effective treatment solutions for rural areas: Design and operation of a new package treatment plant for single households. Water Sci. Technol. 2004, 48, 107-114.

4. Metcalf \& Eddy Inc. Wastewater Engineering: Treatment, Disposal, and Reuse, 4th ed.; McGraw-Hill: New York, NY, USA, 2003.

5. Nakajima, J.; Fujimura, Y.; Inamori, Y. Performance evaluation of on-site treatment facilities for wastewater from households, hotels and restaurants. Water Sci. Technol. 1999, 39, 85-92.

6. Akhondi, E.; Zamani, F.; Tng, K.H.; Leslie, G.; Krantz, B.W.; Fane, G.A.; Chew, J.W. The performance and fouling control of submerged hollow fiber (HF) systems: A review. Appl. Sci. 2017, 7, 765.

7. Chung, J.W.; Edewi, O.C.; Foppen, J.W.; Gerner, G.; Krebs, R.; Luc Lens, P.N. Removal of Escherichia coli by intermittent operation of saturated sand columns supplemented with hydrochar derived from sewage sludge. Appl. Sci. 2017, 7, 839.

8. Abrha, Y.W.; Kye, H.; Kwon, M.; Lee, D.; Kim, K.; Jung, Y.; Ahn, Y.; Kang, J.W. Removal of algae, and taste and odor compounds by a combination of plant-mineral composite (PMC) coagulant with UV-AOPs: Laboratory and pilot scale studies. Appl. Sci. 2018, 8, 1502. 
9. Morales-Polo, C.; Cledera-Castro, M.; Moratilla Soria, B. Reviewing the anaerobic digestion of food waste: From waste generation and anaerobic process to its perspectives. Appl. Sci. 2018, 8, 1084.

10. Wu, S.; Austin, D.; Liu, L.; Dong, R. Performance of integrated household constructed wetland for domestic wastewater treatment in rural areas. Ecol. Eng. 2011, 37, 948-954.

11. Chen, G.Q.; Shao, L.; Chen, Z.M.; Li, Z.; Zhang, B.; Chen, H.; Wu, Z. Low-carbon assessment for ecological wastewater treatment by a constructed wetland in Beijing. Ecol. Eng. 2011, 37, 622-628.

12. Ma, T.; Zhang, L.; Xia, B.; Xiong, Y.; Yu, P.; Lia, G.; Lia, J.; Zhao, C. Treatment of farmer household tourism wastewater using iron-carbon micro-electrolysis and horizontal subsurface flow constructed wetlands: A full-scale study. Ecol. Eng. 2018, 110, 192-203.

13. Álvarez, J.A.; Ruíz, I.; Soto, M. Anaerobic digesters as a pretreatment for constructed wetlands. Ecol. Eng. 2008, 33, 54-67.

14. Abou-Elela, S.I.; Golinielli, G.; Abou-Taleb, E.M.; Hellal, M.S. Municipal wastewater treatment in horizontal and vertical flows constructed wetlands Ecological Engineering 61. Ecol. Eng. 2013, 61 Pt A, 460-468.

15. Alvarez-Zaldívar, P.; Centler, F.; Maier, U.; Thullner, M.; Imfeld, G. Biogeochemical modelling of in situ biodegradation and stable isotope fractionation of intermediate chloroethenes in a horizontal subsurface flow wetland. Ecol. Eng. 2016, 90, 170-179.

16. Andreo-Martínez, P.; García-Martínez, N.; Quesada-Medina, J.; Almela, L. Domestic wastewaters reuse reclaimed by an improved horizontal subsurface-flow constructed wetland: A case study in the southeast of Spain. Bioresour. Technol. 2017, 233, 236-246.

17. Bruun, J.; Pugliese, L.; Hoffmann, C.C.; Kjaergaard, C. Solute transport and nitrate removal in full-scale subsurface flow constructed wetlands of various designs treating agricultural drainage water. Ecol. Eng. 2016, 97, 88-97.

18. Butterworth, E.; Dotro, G.; Jones, M.; Richards, A.; Onunkwo, P.; Narroway, Y.; Jefferson, B. Effect of artificial aeration on tertiary nitrification in a full-scale subsurface horizontal flow constructed wetland. Ecol. Eng. 2013, 54, 236-244.

19. Metcalf and Eddy, Inc. Wastewater Engineering: Treatment, Disposal, and Reuse, 3rd ed.; McGraw-Hill, Inc.: Singapore, 1991.

20. Fan, Z.H.; Wang, W.H. A review on organic pollution removal efficiency by gravel contact oxidation treatment. Environ. Prot. Soc. 2006, 29, 91-102.

21. Kinnicutt, L.P. The prevention of the pollution of streams by modern methods of sewage treatment. Science 1902, 16, 161-171.

22. Seidel, K. Pflanzungen Zwischen Gewässern und Land; Mitteilungen Max-Planck Gesselschaft: Bonn, Germany, 1953; pp. 17-20.

23. Seidel, K. Die Flechtbinse Scirpus lacustris. In Őkologie, Morphologie und Entwicklung, ihre Stell Bedeutung; Schweizerbart'sche Verlagsbuchnadlung: Stuttgart, Germany, 1955; pp. 37-52.

24. Darcy, H. Rapport à le Maire et au Conseil Municipal, de Dijon, sur les Moyens de Fournir l'Eau Nécessaire à cette Ville; Douillier: Dijon, France, 1834.

25. Darcy, H. Rapport à M. le Ministre des Travaux Publics, sur le pavage et le macadamisage des chaussées de Londres et de Paris. Ann. Ponts Chaussées Ser. 1850, 2, 1-264.

26. Darcy, H. Les Fontaines Publiques de la Ville de Dijon; Dalmont: Paris, France, 1856.

27. Darcy, H. Recherches Experimentales Relatives au Mouvement de l'Eau dans les Tuyaux; Mallet-Bachelier: Paris, France, 1857.

28. Darcy, H. Relative à quelques modifications à introduire dans le tube de Pitot. Ann. Ponts Chaussées Ser. 1858, 3, 351-359.

29. Kadlec, R.H.; Knight, R.L. Treatment Wetlands; Lewis Publishers: New York, NY, USA, 1996. 